\title{
Seven criteria to treat Scheuermann's Disease Biagio Iemolo
}

\author{
Address: Azienda Ospedaliera Gravina - Caltagirone, via Gulfi n.20; Pedalino c.a.p. 97010, Italy \\ Email: Biagio Iemolo - biagioiemolo@tiscali.it
}

from 4th International Conference on Conservative Management of Spinal Deformities

Boston, MA, USA. 13-16 May 2007

Published: 12 October 2007

Scoliosis 2007, 2(SuppI I):S39 doi:10.1186/1748-716I-2-SI-S39

This abstract is available from: http://www.scoliosisjournal.com/content/2/SI/S39

(c) 2007 lemolo; licensee BioMed Central Ltd.

\section{Objective}

In our spine center, we observe adolescents who present clinical cases of bony spinal dystrophy during growth, without typical clinical and especially the radiological features of Scheuermann's disease. Such borderline cases ('pre-Scheuermann'?) [1] which cannot be easily classified, need prompt careful and appropriate answers in terms of therapy. We find that existing classifications of Scheuermann's disease are restricting and do not include various types of spinal irregularity and clinical abnormalities of our patients [1]. Our purpose is to present seven criteria to define easily all forms of Scheuermann's disease.

\section{Study design}

Four clinical criteria and three radiological criteria are proposed for immediate evaluation of deformity. The clinical criteria are: age, level (classic or atypical), pain, spinal rigidity. The three radiological criteria are: degrees (Cobb), vertebral irregularity, wedging.

\section{Results}

We scored the points of each criterion to define the categories of kyphosis and quantify the magnitude of the spinal deformity. These criteria are used easily to recognize all the categories of patients and to describe indications for treatment.

\section{Conclusion}

The point of our work is quite practical. Seven criteria are provided to orient diagnosis, anatomic findings, clinical symptoms, radiographic findings, orthotic or other nonoperative treatment with cast, and operative treatment.
Early diagnosis, with prompt bracing, is key in optimal treatment.

\section{References}

I. Wenger DR, Frick SL: Scheuermann's kyphosis. Spine 1999, 24:2630-2639. 